\title{
A ATUAÇÃO DAS AGÊNCIAS REGULADORAS DE ENERGIA PARA O DESENVOLVIMENTO SUSTENTÁVEL: ANÁLISE COMPARADA ENTRE BRASIL E PORTUGAL
}

\author{
Mariane Silva de Castro*1 \\ Veríssimo Nascimento Ramos dos Santos*2
}

\begin{abstract}
RESUMO: O presente trabalho tem como objetivo relacionar o novo papel do Estado com o paradigma da regulação, frente aos desafios da sustentabilidade. A regulação no setor da eletricidade surgiu com a finalidade de promover uma gestão de mercado mais produtiva, contudo, no novo paradigma da sustentabilidade esta não poderia olvidar os aspectos assegurados pelas normas ambientais já existentes. Por isso, busca-se a análise da atuação das Agências Reguladoras da Energia para a concretização do desenvolvimento sustentável, fazendo uma análise comparada entre Brasil e Portugal, objetivando obter resultados das políticas destas agências com relação à promoção de políticas de eficiência energética.
\end{abstract}

Palavras-chaves: Estado. Agências Reguladoras. Desenvolvimento Sustável. Eficiência Energética.

\section{THE PERFORMANCE OF ENERGY REGULATORY AGENCIES FOR SUSTAINABLE DEVELOPMENT: A COMPARATIVE ANALYSIS BETWEEN BRAZIL AND PORTUGAL}

\begin{abstract}
This study aims to correlate the new state issue with the regulation paradigm for sustainability challenges. The regulation in the field of electricity has the aim of promoting a productive market management however, in the new paradigm of sustainability this could not forget the aspects ensured by existing environmental standards. Wherefore, the objective of the present study is an analysis of the Energy Regulatory Agencies for the achievement of sustainable development, making a comparative analysis between Brazil and Portugal, aiming to verify the results of the regulation agency's policies in relation to the real promotion of energy efficiency policies.
\end{abstract}

Keywords: State. Regulation Agency. Sustainable Development. Energy Efficiency.

\footnotetext{
${ }^{1}$ Mariane Silva de Castro é graduada em Direito (UFMA) e Pedagogia (UFMA), mestranda em Ciências JurídicoPolíticas, especialidade em Direito Administrativo pela Universidade de Lisboa. E-mail: marianecastro17@gmail.com. Endereço postal: Rua de Santiago, 33, Centro, São Luís - MA, CEP: 65015-450.

${ }^{2}$ Veríssimo Nascimento Ramos dos Santos é bacharel em Direito (UFMA) e Administração (UEMA), mestre em Administração pela Universidade Federal Fluminense (UFF), especialista em Direito Administrativo (IDP). Atualmente é professor do Instituto Federal de Ciência e Tecnologia do Maranhão (IFMA). E-mail: verissimo.santos@ifma.edu.br . Endereço postal: Rua Via Láctea, quadra 13, casa 01, Recanto dos Vinhais, São Luís - MA, CEP: 65070-620
} 


\section{INTRODUÇÃO}

O presente artigo tem como objeto de estudo das agências reguladoras do setor da energia, um tema que ocupa interesse à medida em que esta tem sido tangenciada pela problemática ambiental. Os novos paradigmas da sustentabilidade têm influenciado as decisões do Estado no que tange ao surgimento de um Direito Ambiental comprometido com as necessidades das gerações futuras.

A importância da questão ambiental na área da energia está na pauta do dia, ocupando sempre manchetes globais e forçando as principais potencias mundiais a se unirem em prol de um objetivo comum: lutar contra o aquecimento global e garantir níveis satisfatórios de qualidade de vida ao homem e a todo ecossistema, sem que ocorra um colapso no desenvolvimento econômico.

Assim, entende-se que a sustentabilidade está no cerne da questão do desenvolvimento econômico deste século, onde este, necessariamente, precisa estar aliado a um modelo que priorize a responsabilidade da exploração dos recursos naturais, de modo que não haja impactos danosos e irreversíveis para as próximas gerações.

Essas e outras preocupações foram exaustivamente debatidas pelas maiores lideranças democráticas deste século e do anterior, as quais tiveram suas diretrizes balizadas pela Organização das Nações Unidas (ONU) a fim de demarcar metas que garantissem que os objetivos ambientais firmados pelos acordos internacionais servissem de standarts para todos os países signatários, com o fulcro maior de alcançar um nível de consciência ambiental global, não só entre os países desenvolvidos, mas também entre os países em desenvolvimento.

Diante desta realidade de mudanças ambientais e acordos internacionais em busca de parâmetros ecologicamente sustentáveis nasce, assim, um novo papel das agências reguladoras da área de energia, as quais necessariamente perpassam por uma busca por energias limpas e renováveis.

É neste contexto que emergem a figura das agências reguladoras o propósito de tornar a Administração Pública mais eficiente e autônoma, de modo que fomentem um modelo econômico com menores riscos de mercado e falhas operacionais. Deste novo movimento, onde a agências reguladoras têm papel primordial na manutenção e desenvolvimento de setores estratégicos de um Estado, pretende-se analisar qual o esforço desempenhado no setor da energia para a promoção do desenvolvimento sustentável. 


\section{A ATUAÇÃO DAS AGÊNCIAS REGULADORAS DE ENERGIA PARA 0 DESENVOLVIMENTO SUSTENTÁVEL: ANÁLISE COMPARADA ENTRE BRASIL E PORTUGAL}

Desta forma, delimita-se como objeto de estudo a atuação das agências reguladoras do setor de energia no Brasil e em Portugal, neste novo contexto da sustentabilidade. Pretendese analisar se as medidas de eficiência energética e objetivos governamentais nos últimos anos têm sido voltados para a consolidação de uma política energética sustentável, analisando os quais foram os avanços ou retrocessos.

O presente artigo foi elaborado através de pesquisa bibliográfica e doutrinária majoritariamente portuguesa e brasileira. Não obstante, foram analisados dados das agências reguladoras da energia através dos sites oficiais dos governos portugueses e brasileiros.

Por fim, almeja-se que este trabalho contribua para uma discussão salutar sobre os resultados das políticas regulatórias na área da energia sob o ponto de vista da sustentabilidade.

\section{O “NOVO” PARADIGMA DA SUSTENTABILIDADE E AS QUESTÕES ENERGÉTICAS}

Nas páginas a seguir analisa-se o surgimento do conceito jurídico do princípio do desenvolvimento sustentável e em paralelo será esmiuçado o contexto internacional que circundou toda esta problemática ambiental. Este plano de fundo é necessário para que seja compreendido o porquê da questão energética ter se tornado uma preocupação global.

Não é recente o pensamento de que os recursos naturais da terra são finitos. A crise do petróleo em 1970 expôs a fragilidade de um modelo de exploração energético baseado em um único recurso e como bem pontuou o doutrinador Vasco Pereira da Silva (2005, p.18), esta crise fomentou o desenvolvimento de uma "consciência dos limites de crescimento econômico e da esgotabilidade dos recursos naturais”.

Assim, os combustíveis fósseis se apresentaram como uma opção “finita, poluente e cara" (SOARES, 2014, p. 13). Foi neste contexto que as tragédias de cunho ambiental começaram a ser vistas com um outro olhar. Destaca-se a importância do relatório The Limits of Growth, elaborado por cientistas do Massachussets Institut of Technology (MIT) que revelou, pela primeira vez, que a degradação ambiental já havia se tornado um problema global de sinais alarmantes. O prognóstico inicial certificou que o desgaste do ecossistema global é fruto de uma exploração secular irresponsável em busca de produção de riquezas, que é a mola propulsora do desenvolvimento econômico de toda nação. Fez-se urgente repensar uma forma de desenvolvimento que não prejudicasse o bem-estar ambiental das gerações futuras. 
Neste aspecto, não se olvida que o surgimento da problemática ambiental também resultou na garantia de um direito fundamental. Sobre esta discussão doutrinária sobre a ciência jurídica ambiental, reconhece-se que a doutrina não é pacífica quanto a classificação da geração de direitos humanos, a qual pertence o direito ao ambiente.

Para doutrinador português Vasco Pereira da Silva (2005, p. 102), este direito está inserido na terceira geração de direitos humanos pois este "apresenta em simultâneo uma vertente negativa, que garante ao seu titular a defesa contra agressões ilegais no domínio constitucionalmente garantido, e uma vertente positiva, que obriga à actuação das entidades públicas para a sua efectivação”, contudo para o brasileiro Édis Milaré (2009) e o espanhol Gregório Peces-Barba Martinez (1993) o direito do ambiente pertence a uma quarta geração de direitos humanos, visto o seu caráter pós-moderno.

É dentro deste contexto de mudança de paradigmas ambientais que se pretende analisar a questão energética.

Diante deste panorama sob o imperativo de preservação do ambiente, surgiu o conceito de desenvolvimento sustentável como aquele capaz de suprir as necessidades da geração atual, sem comprometer a capacidade de atender as necessidades das futuras gerações. Contudo, cabe explicar que existiu toda uma agenda internacional (SANDS, 2017) por trás desse nível de conscientização ambiental que inaugurava o conceito de sustentabilidade. (SARAIVA, 2017)

Neste estudo verificou-se que tanto Portugal quanto o Brasil, adotaram em suas Cartas Magnas, o princípio constitucional do desenvolvimento sustentável.

Em Portugal, o princípio está expressamente consagrado no artigo $66^{\circ}$, número 2 da Constituição da República Portuguesa (CRP) que ratifica: "Para assegurar o direito ao ambiente, no quadro de um desenvolvimento sustentável, incumbe ao Estado, por meio de organismos próprios e com o envolvimento e a participação dos cidadãos”.

O doutrinador português Vasco Pereira da Silva (2005), afirma que o princípio constitucional do desenvolvimento sustentável obriga da "fundamentação ecológica" das decisões jurídicas de desenvolvimento econômico, estabelecendo a necessidade de ponderar tanto os benefícios de natureza econômica, como os prejuízos de natureza ecológica de uma determinada medida.

No Brasil, o artigo que se encontra explícito este princípio é o artigo 225 da Constituição da República Federativa do Brasil: “Todos têm direito ao meio ambiente 


\section{A ATUAÇÃO DAS AGÊNCIAS REGULADORAS DE ENERGIA PARA 0 DESENVOLVIMENTO SUSTENTÁVEL: ANÁLISE COMPARADA ENTRE BRASIL E PORTUGAL}

ecologicamente equilibrado, (...) essencial à sadia qualidade de vida, impondo-se ao Poder Público e à coletividade o dever de defendê-lo e preservá-lo para as presentes e futuras gerações”.

Como já fora mencionado, a crise do petróleo de 1970 expôs o problema de uma economia completamente dependente de combustíveis fósseis. Este modelo começou a ser questionado por outro motivo: a emissão de dióxido de carbono proveniente da queima deste recurso natural. (SOARES, 2014)

Antes de adentar especificamente ao assunto, se faz importante voltar um pouco mais na história para que se possa compreender os elementos que corroboraram para a eclosão da primeira grande crise energética mundial.

A problemática da exploração de recursos naturais para obtenção de energia não é recente. Acredita-se que foi com o surgimento da máquina de vapor, ainda no século XVIII, e com o advento do motor de combustão interna, no século XIX, que o mundo presenciou o crescimento econômico potencialmente relevante. A revolução industrial trouxe consigo uma nova forma de produzir e a exploração do carvão, do petróleo e seus derivados se tornaram a mola-propulsora desse modelo.

Após do fim da primeira guerra mundial, o petróleo se tornou um produto estratégico para o mundo, visto o seu uso refinado em diesel, o qual era utilizado em combustível para submarinos e aviões. Logo, a versatilidade do petróleo foi o fator chave para torná-lo em um produto comercial de alto valor no mercado mundial.

Foi justamente por conta desse alto valor de mercado, que os principais países detentores da produção e exportação de petróleo criaram a Organização dos Países Exportadores de Petróleo (OPEP) em 1960, composta inicialmente pelo Iraque, Kuwait, Arábia Saudita e Venezuela. Utilizando-se de controle sobre os recursos petrolíferos e impondo uma nova relação de domínio no setor, a OPEP utilizou da teoria das leis de mercado, forçando uma redução na produção, para que houvesse uma alta no preço do petróleo comercializado. As consequências dessas medidas resultaram na primeira crise do petróleo de 1973 e que foram acompanhadas subsequentemente por outras, em 1974 e 1979.

O efeito deste colapso forçou os países dependentes economicamente do petróleo e a repensar novas formas de obter energia para o desenvolvimento das suas atividades 
econômicas, desta forma, afirma-se que este evento desnudou a vulnerabilidade a que está imposta uma nação cuja economia é dependente uma única matriz energética.

O nacionalismo aliado à tecnologia impulsionou o desenvolvimento de matrizes energéticas ainda não exploradas. Em torno de um panorama onde pouco se falava sobre sustentabilidade, não foi ao primeiro instante que foram privilegiadas as fontes de energias renováveis, tais como a solar, eólica e de biomassa.

A consciência ambiental e a agravante descoberta do aquecimento global exigiram uma mudança de paradigma com relação a exploração do petróleo e seus derivados. Calcula-se que até a década anterior, por volta de $80 \%$ das fontes primárias de energia eram provenientes de combustíveis fósseis: carvão, petróleo e gás natural. (SANTOS, 2011)

Como fora exposto no tópico anterior, a ONU teve papel primordial na construção de uma agenda internacional para o meio ambiente. Após a Conferência de Estocolmo em 1972, outro evento de importância para a temática ambiental, e especialmente para a área de energia, foi a Conferência das Nações Unidas sobre o Meio Ambiente e o Desenvolvimento (Rio 92). Na visão de Alexandre Kiss (1994), este evento superou o de Estocolmo, pois consagrou os princípios fundamentais que se desenharam desde o fim da década de 60 e enuncia outros, tais como os princípios da participação dos cidadãos, da avaliação prévia dos efeitos sobre o ambiente e da prevenção. Deste evento surgiram cinco documentos assinados pelas 185 nações presentes, quais foram: a Agenda 21, a Convenção das Nações Unidas sobre Diversidade Biológica, a Convenção Combate à Desertificação e a Convenção-Quadro das Nações Unidas sobre a Mudança do Clima (CQNUMC).

Reconhece-se a importância da CQNUMC para surgimento do Protocolo de Quioto em 1997, que teve como objetivo a redução das taxas de emissões de Gases com Efeito Estufa (GEE), os quais foram diretamente associados com a problemática do aquecimento global. Esta associação só fora possível devido a maior atenção aos problemas ambientais.

Assim, constatou-se que a combustão dos derivados do petróleo, combinada a devastação do solo, através da deflorestação, têm impactos diretos no desequilíbrio da temperatura do planeta. Isto, pois a queima de combustíveis fósseis gera grandes quantidades de dióxido de carbono $\left(\mathrm{CO}_{2}\right)$ na atmosfera ${ }^{3}$, sendo este um gás de efeito estufa, pois absorve a radiação infravermelha.

\footnotetext{
${ }^{3}$ Mensura-se que a concentração atmosférica de $\mathrm{CO}_{2}$ cresceu desde 280 ppmv (partes em milhão em volume) antes da revolução industrial at'w 384 ppmv em 2007.
} 


\section{A ATUAÇÃO DAS AGÊNCIAS REGULADORAS DE ENERGIA PARA 0 DESENVOLVIMENTO SUSTENTÁVEL: ANÁLISE COMPARADA ENTRE BRASIL E PORTUGAL}

Ao aumentar a concentração de gases de efeito estufa, o planeta sofre com as alterações climáticas, visto que há um desequilíbrio ambiental atmosférico. Uma das mais graves consequências de toda esta questão é a alteração do sistema climática e o aumento da temperatura média global da troposfera.

Segundo relatórios do Painel Intergovernamental sobre Mudanças Climáticas ${ }^{4}$ (IPCC, 2007) de 2007 de 1995 a 2006 foram registradas as mais altas temperaturas médias globais desde 1850. Boa parte da energia climática do planeta tem sido absorvida pelos oceanos, cuja temperatura aumentou em profundidades até três mil metros, o que projeta cenários de aumento médio do mar de até 1,4 metro até o ano de 2100. (RAHMSTORF, 2007)

Em esfera mundial, ficou patente o problema do aquecimento global e a importância de descarbonização da economia mundial, emergindo a necessidade de se repensar a menor dependência dos combustíveis fósseis e a maior utilização de tecnologias capazes de contribuir para a equilíbrio dos gases de efeito estufa da atmosfera.

Assim, as Fontes de Energia Renováveis (FER) ganharam força no cenário mundial devido seus vários benefícios, como bem demostrou os estudos de Cláudia Dias Soares e Suzana Tavares da Silva (2014):

a) por ser um investimento estratégico, uma vez que promove a diminuição da dependência energética em uma só fonte de energia;

b) por trazer consigo uma vertente social, culminando na geração de emprego, fixação de populações e combate à desertificação;

c) promover o desenvolvimento sustentável, uma vez que comparado aos combustíveis fósseis, são reduzidos os gases de efeito estufa;

d) e por fim, também trazem benefícios econômicos, vez que promovem atividades de geração de riqueza através da redução da fatura energética.

Contudo, apesar dos esforços para diversificação da matriz energética no mundo, a indústria do petróleo ainda detém forte influência na economia global e a as tendências gerais sobre energia não são das mais favoráveis. É o que se expõe a seguir através do relatório compilado por Nicole Gnesotto e Giovanni Grevi (2008, p. 57-58):

a) Até 2025 a procura mundial de energia primária deverá crescer em média aproximadamente 1,6 ao ano. Em 2030, as necessidades energéticas poderão ser 50\% superiores às necessidades atuais.

\footnotetext{
${ }^{4}$ Intergovernmental Panel on Climate Change (em português: Painel Intergovernamental sobre Mudanças Climáticas). É uma organização científico-política criada em 1988 no âmbito das Nações Unidas (ONU) pela iniciativa do Programa das Nações Unidas para o Meio Ambiente (PNUMA). In: IPCC, 2007, Intergovernmental Panel on Climate Change. Constributions of Working Group I, II and III to the IPCC Fourth Assessment Report, Cambridge University Press.
} 
b) Os combustíveis fósseis petróleo gás e carvão continuaram a ser as principais fontes de energia primária do planeta, representando 81\% da procura. O petróleo deverá continuar a ser a fonte de energia mais utilizada. O carvão deverá continuar ocupa o segundo lugar devido a uma ligeira diminuição da procura previsível de gás. A procura de carvão e gás deverá registrar crescimento manuais bastante semelhantes (1,8\% e $2 \%$ por ano, respectivamente, neste período).

c) A parte da energia nuclear deverá diminuir na maioria dos países industrializados e progredir nos países em desenvolvimento e nas economias emergentes. As energias renováveis (à excepção da biomassa) registrar amo crescimento mais rápido do que as outras fontes de energia, nos países da OCDE, embora continuem a constituir apenas uma parte mínima da oferta mundial.

d) Os países em desenvolvimento, por si só, representaram mais de dois terços do aumento da procura energética. No entanto, as disparidades regionais continuarão a ser importantes, com a Ásia, a registrar um crescimento (em volume) muito superior ao de África. A procura também aumentar a na zona da OCDE, mas a um ritmo inferior. A dependência das importações energéticas por parte dos países desenvolvidos e emergentes intensificar-se-á sensivelmente.

e) Os recursos energéticos estarão, muito provavelmente, em condições de responder ao aumento da procura, mas a optimização da sua exploração depende inteiramente de investimentos. Além disso, embora a oferta e a procura energéticas devam crescer, a primeira poderá progredir mais devagar que a segunda, o que provocar uma subida dos preços da energia.

Diante de um cenário catastrófico, defende-se que o desenvolvimento sustentável com relação a área da energia, integre e racionalize os sistemas de produção de energia renováveis e endógenas, como a: solar fotovoltaica, solar-térmica, biocombustíveis, biogás, biomassa, geotérmica, oceanos, mini-hídrica e eólica. Por outro lado, não se deve esquecer que é fundamental integrar os sistemas de eficiência energética, e também os indicadores de consumo e racionalização. (CORREIA, 2009)

E é com base no entendimento que a energia é um bem econômico e por isso se sujeita às regras de mercado (FERNANDES, 2011), que se pretende analisar os próximos capítulos deste trabalho, relacionando a atuação das agências reguladoras da área de energia, para a promoção do novo paradigma do desenvolvimento sustentável.

\section{A REGULAÇÃO NA ADMINISTRAÇÃO PÚBLICA}

Neste capítulo, será estudado o papel das agências reguladoras no âmbito da Administração Pública. Para tanto, será analisado um contexto histórico, o qual se explicitará qual a necessidade que supre estas entidades. A seguir, será analisado o seu conceito na atualidade e, por fim, será analisado o desempenho da função destas entidades para a regulação da área energética. 


\section{A ATUAÇÃO DAS AGÊNCIAS REGULADORAS DE ENERGIA PARA 0 DESENVOLVIMENTO SUSTENTÁVEL: ANÁLISE COMPARADA ENTRE BRASIL E PORTUGAL}

A regulação nasce pela necessidade de transformar o serviço público essencial em mais eficiente e mais acessível à sociedade, servindo-se de uma lógica mais técnica - o que a difere da concepção usual dos serviços estatais comuns. Como bem conceituou Ana Roque (2004, p. 11), a regulação é “uma solução de recurso para fazer face à inevitabilidade das falhas de mercado”. Surge, portanto, como uma tentativa de tornar setores estratégicos da economia com um tratamento diferenciado do que o restante dos serviços públicos.

Deste modo, surge uma nova figura de Estado, o qual é denominado de regulador. Este Estado Regulador tem como atributo a prioridade da competência regulatória, que se dá pela excepcionalidade da prestação direta de atividades econômicas pelo próprio Estado.

Para Marçal Justen Filho (2009) um Estado regulador caracteriza-se: pela transferência para a iniciativa privada de atividades desenvolvidas pelo Estado (desde que dotadas de forte cunho de racionalidade econômica); liberalização de atividades até então monopolizadas pelo Estado, a fim de propiciar a disputa pelos particulares em regime de mercado; a presença do Estado no domínio econômico, que privilegia a competência regulatória; a atuação regulatória do Estado, que se norteia não apenas para atenuar ou eliminar os defeitos do mercado, mas também para realizar certos valores de natureza política ou social; e institucionalização de mecanismos de disciplina permanente das atividades reguladas.

É fundamental aqui, destacar regulação econômica no ordenamento jurídico no Brasil e em Portugal.

Iniciando pela Constituição brasileira, é notório que a CRFB permitiu a intervenção direta e indireta na área econômica, estas são encontradas no Título VII da Ordem Econômica e Financeira. De modo indireto pode, o Estado, explorar atividade econômica por monopólio ou concorrência, como baliza o artigo 173 caput e parágrafo $1^{\circ}$ da CRFB. No artigo 174 da CRFB, há previsão para a intervenção indireta onde se refere: “como agente normativo e regulador da atividade econômica, o Estado desempenhará, na forma da lei, as funções de fiscalização, incentivo e planejamento”.

Em Portugal, pode-se afirmar que a regulação foi inserida através art. 267. ${ }^{\circ}$, n. ${ }^{\circ} 3$ da CRP prescreve, sob a epígrafe "Estrutura da Administração" e sob o título IX relativo à "Administração Pública" que "a lei pode criar entidades administrativas independentes". Não obstante, o artigo 9, alínea “d”, da CRP, onde constam as tarefas fundamentais do Estado, 
explicitam que é dever do Estado "promover o bem-estar e a qualidade de vida do povo (...) mediante a transformação e modernização das estruturas económicas e sociais”.

Ana Roque (2004) defende que este último artigo deve ser interpretado segundo o núcleo da intervenção indireta Estatal, de modo a ser assegurado pelo Estado a garantia dos direitos e liberdades fundamentais, com respeito aos princípios democráticos do Estado de Direito.

Desta forma, fica patente que tanto no Brasil quanto em Portugal há disciplinada a existência da intervenção direita e indireta do Estado na ordem econômica. Tornando constitucional a disciplina deste trabalho no que tange ao papel das agências reguladoras para a exploração da energia.

Adentrando especificamente ao assunto das agências reguladoras para energia, é sabido que estas foram criadas pelo Estado com o escopo de atender aos anseios de uma ordem econômica mais moderna, onde era necessária a regulação de setores essenciais ao desenvolvimento da nação.

Desta forma, a busca por uma gestão energética mais eficiente teve como passo primordial a diversificação das fontes e energia, de modo a evitar futuros colapsos ou as chamadas falhas de mercado. (CONFRARIA, 2011)

A regulação da economia entrou, assim, para a área da energia segundo a necessidade de controlar bens e serviços oferecidos pelo Estado, de modo a assegurar os investimentos e o alinhamento com as necessidades dos consumidores.

Desta forma, superar a barreira das falhas de mercado para a área da energia implica diretamente em incentivar a competitividade entre empresas prestadoras de serviços a aumentarem os seus níveis de eficiência energética.

De modo a problematizar essa questão, Gomes cita Herring, que afirma que as políticas de eficiência energética acabam por incentivar um aumento de consumo, por isso não pode ser entendida como uma política ambiental eficiente (HERRING, 2006 apud GOMES, 2016a). Da mesma forma relata a visão de Rudin, que a eficiência energética incentiva uma crescente procura ao uso de recursos naturais. (RUDIN, 1999 apud GOMES, 2016b)

Neste estudo, entende-se que o novo paradigma da eficiência energética é necessário para que implementem políticas de controle mais palpáveis sobre os planos de ação das agências reguladoras. Isto, pois, sabe-se que a expansão da oferta de energia não poderá mais ser programada de acordo apenas com as leis de mercado, é necessário que se tenha 


\section{A ATUAÇÃO DAS AGÊNCIAS REGULADORAS DE ENERGIA PARA O DESENVOLVIMENTO SUSTENTÁVEL: ANÁLISE COMPARADA ENTRE BRASIL E PORTUGAL}

mecanismos políticos a longo prazo que busquem a independência dos combustíveis fósseis (que contribuem para o descontrole do aquecimento global), que invistam na exploração de fontes de energias renováveis e que aumentem o controle sobre o desperdício de energia. (GOMES, 2016a)

Desta forma, defende-se que a regulação pode sim, beneficiar os planos de eficiência energética. Ocorre que ainda é difícil conciliar interesses entre as empresas reguladas, o Estado e os consumidores. Portanto, defende-se como necessário um impulso maior por parte do Estado, tanto para a conscientização da sociedade sobre a importância do consumo sustentável da energia, quando para a o incentivo de energias limpas e a desburocratização legal no que tange aos novos regulamentos com relação a implementação de políticas de eficiência energética às empresas reguladas. (GOMES, 2016b)

\section{A ATUAÇÃO DAS AGÊNCIAS REGULADORAS DE ENERGIA PARA O DESENVOLVIMENTO SUSTENTÁVEL: ANÁLISE COMPARADA ENTRE BRASIL E PORTUGAL}

Neste capítulo pretende-se analisar propriamente a atuação das agências reguladoras de energia no Brasil em Portugal no que tange a medidas de adequação que privilegiem o desenvolvimento da sustentabilidade em ambos os países, expondo o problema jurídico da regulação versus a busca pela sustentabilidade.

Antes de adentrar ao próximo tópicos, é necessário identificar que no Brasil a agência reguladora para energia no Brasil é a Agência Nacional de Energia Elétrica (ANEEL) e em Portugal, a Entidade Reguladora dos Serviços Energéticos (ERSE).

4.1 O papel das ANEEL e ERSE para a promoção da sustentabilidade

Inicialmente cabe aqui comparar a função desempenhada pela ANEEL e pela ERSE quanto agências reguladoras para energia.

A ANEEL está localizada na Administração Pública indireta da Brasil, ocupando o lugar de autarquia em regime especial, diretamente vinculada ao Ministério de Minas e Energia. Tem como maior objetivo a regulação do setor elétrico brasileiro e encontra-se balizada por meio da Lei no 9.427/1996 e Decreto $n^{\circ}$ 2.335/1997. (BRASIL, 2017) 
Em Portugal a ERSE ${ }^{5}$, tem a natureza jurídica de pessoa coletiva de direito público dotada de autonomia administrativa e financeira, dispondo de patrimônio próprio e asseguradas sua independência funcional. Fora criada pelo Decreto-Lei número 187/95, de 27 de julho, e cujos Estatutos foram aprovados pelo Decreto-Lei número 44/97, de 20 de fevereiro, passando a denominar-se por Entidade Reguladora dos Serviços Energéticos.

É a entidade responsável pela regulação dos setores do gás natural e da eletricidade, conservando a sigla ERSE e é disciplinada pelos seus Estatutos aprovados pelo Decreto-Lei n. o 97/2002, de 12 de abril, alterados pelo Decreto-Lei n. ${ }^{\circ}$ 212/2012, de 25 de setembro, na redação do Decreto-Lei n. ${ }^{\circ}$ 84/2013, de 25 de junho (PORTUGAL, 2017).

Neste primeiro critério, pode-se observar que ambos países adotaram agência reguladoras independentes de forma certificar a autonomia destes organismos frente as atividades regulatórias as quais são demandadas. Enquanto autarquias independentes, estas foram criadas por lei. No Brasil, tal disposição está assegurada no art. $1^{\circ}$ do DL 2.335/1997 e em Portugal no art. $1^{\circ}$ do DL 97/2002.

Assim, depreende-se os dispositivos legais para as agências reguladoras para energia no Brasil e em Portugal são, respectivamente: Lei 8.987/95, Lei 9.427/1996 e o Decreto $n^{\circ} 2.335$ de 1997; e a Lei n. ${ }^{\circ}$ 67/2013 e o Decreto-Lei no ${ }^{\circ}$ 97/2002. É com base nessas normas legais que será feita a análise comparativa deste tópico.

Sob a primeira análise no quesito promoção de eficiência energética, foi verificado que ambos os países destacaram na norma legal esta preocupação.

No Brasil, o dispositivo está localizado no Artigo 12, inciso III, do Decreto 2335/1997 que as diretrizes da ANEEL devem contemplar a "promoção do uso e da ampla oferta de energia elétrica de forma eficaz e eficiente, com foco na viabilidade técnica, econômica e ambiental das ações”.

Em Portugal, o diploma do Estatuto da Entidade Reguladora dos Serviços Energéticos (ERSE) DL nº 97/2002, assegurou de forma mais enfática a eficiência energética, nos artigos $2^{\circ}$ e $3^{\circ}$ do referido Decreto Lei. Isto, pois, foi verificada quatro citações sobre a necessidade de se assegurar a eficiência energética na agência reguladora, o que demonstra

\footnotetext{
${ }^{5}$ A ERSE rege-se ainda pelas regras aplicáveis às entidades reguladoras, nos termos definidos pela Lei-quadro das entidades administrativas independentes com funções de regulação da atividade económica dos setores privado, público e cooperativo, aprovada pela Lei n. ${ }^{\circ}$ 67/2013, de 28 de agosto, alterada pela Lei n. ${ }^{\circ}$ 12/2017, de 2 de maio. A Lei n. ${ }^{\circ}$ 9/2013, de 28 de janeiro aprova o regime sancionatório do setor energético, enquadrando as competências sancionatórias da ERSE no âmbito do Sistema Nacional de Gás Natural e Sistema Elétrico Nacional.
} 


\section{A ATUAÇÃO DAS AGÊNCIAS REGULADORAS DE ENERGIA PARA 0 DESENVOLVIMENTO SUSTENTÁVEL: ANÁLISE COMPARADA ENTRE BRASIL E PORTUGAL}

maior preocupação com o tema em questão quando relacionado ao Brasil. A primeira citação se encontra no artigo $2^{\circ}, n^{\circ} 3$ que dispõe sobre Regime e Independência (o qual foi alterado mais recentemente pelo DL n. ${ }^{\circ} 84 / 2013$, de 25/06), a segunda encontra-se no artigo $3^{\circ}, n^{\circ} 1$, a terceira no artigo $3^{\circ}, n^{\circ} 2$ “d” e a quarta, no artigo $3^{\circ}, n^{\circ} 2$ “y”. Como bem, fora explicitado no texto legal, houve um cuidado em garantir não só a eficiência energética, mas também a sustentabilidade ambiental e do Sistema Elétrico Nacional, não olvidando a eficiência para a promoção da qualidade e da gestão do serviço prestado para a sociedade.

Desta forma, ratifica-se que em Portugal a eficiência energética e a sustentabilidade têm tratamento mais adequado pelo legislador, do que no Brasil.

Com relação à preocupação com a temática ambiental, no Brasil o DL 2.335/1997 afirmou que ANEEL tem como competência estimular e participar de ações ambientais, bem como interagir com o Sistema Nacional de Meio Ambiente, atuando de forma harmônica com a Política Nacional de Meio Ambiental, como dispõe o art. $4^{\circ}$, inciso XXV, do referido texto legal.

Em Portugal, a preocupação ambiental foi demonstrada no DL 97/2002, como bem citado anteriormente no artigo $2^{\circ}, n^{\circ} 3$, no Artigo $3^{\circ}, n^{\circ} 2$, “d”, e também no artigo $41^{\circ}, n^{\circ} 1$, “c” e "h” - último artigo trata dos membros do Conselho Consultivo da ERSE “órgão de consulta na definição das linhas gerais de atuação da ERSE e nas deliberações adotadas pelo conselho de administração" o qual deve ser composto, entre outros, de "um representante do membro do Governo responsável pela área do ambiente” e “um representante da Agência Portuguesa do Ambiente”.

Em linhas gerais, também pode-se observar que a ERSE tem maior abrangência no seu texto legal, do que ANEEL com relação à temática ambiental. Vale salientar, que é de grande valia que o Conselho Consultivo de uma agência reguladora para a área da energia se proponha a acatar as diretrizes de membros especialistas na área do ambiente.

Por fim, quando trata-se de estímulo a novas fontes de energias renováveis, não se verificou nenhuma menção na legislação brasileira. Em Portugal, no DL 97/2002 no artigo 41º, $n^{\circ}$ 1, “k”, garante uma vaga ao Conselho Consultivo da ERSE para “Um representante das associações portuguesas de produtores de energia elétrica a partir de fontes de energia renováveis". 
Desta forma chega-se ao fim deste tópico com análise que no quadro comparativo, a legislação portuguesa está muito além da brasileira, quando se trata de fomentar a sustentabilidade para a agência reguladora do setor de energia. Sem sombra de dúvidas, a experiência legislativa portuguesa poderá ajudar o Brasil na construção de normas legais que estejam mais próximas de uma regulação para a promoção do desenvolvimento sustentável.

\subsection{Análise dos programas de eficiência energética}

Neste último tópico, pretende-se analisar os programas de eficiência energética desenvolvidos pela ANEEL e ERSE, com o fulcro de acompanhar como, de fato, estas agências reguladoras estão se adequando ao novo paradigma da sustentabilidade e se os resultados dessas ações têm sido benéficos para o meio ambiente.

Antes de adentrar ao tema proposto, faz-se salientar que ambos países tiveram em seu passado crises elétricas, por conta de baixa variabilidade da matriz energética.

Portugal tinha como matriz energética até 1960, preponderantemente centrais de carvoarias e o petróleo. De um passado dependente de termoelétricas, o país Ibérico teve como marco o ano de 1997 a inserção de gás natural na matriz energética do país (DIRECÇÃOGERAL DE ENERGIA, 1997), apresentado uma decrescente no índice de dependência em fontes de energia primária a partir da primeira década dos anos 2000. Como ressaltou o estudo de Cláudia Dias Soares e Suzana Tavares da Silva (2014) as fontes de energia renováveis em Portugal nos anos 30 representavam cerca de 3\% do consumo energético, valor que aumentou para 95\% em 1960, regrediu para 31\% em 2000 e aumentou novamente para 35\% em 2009, o destaque deste avanço vai para o incentivo de centrais eólicas.

No Brasil, a matriz elétrica sempre fora dependente do petróleo e das centrais hidrelétricas. Se de alguma forma o Brasil aparece com boa utilização de fontes de energias renováveis, por trás dos números há um grande impacto ambiental causado pela instalação e manutenção das centrais hidrelétricas, motivo que impulsionou a busca por novas matrizes energéticas, como o biodiesel, a energia solar e a eólica.

Diante deste contexto, o papel dos planos de eficiência energética desempenhados pela ANEEL e ERSE, tem como função o incentivo a diversificação da matriz energética.

Começando por Portugal, a eficiência energética fora inserida por programas do governo juntamente com as políticas regulatórias do setor elétrico, cita-se em ordem cronológica os instrumentos: 


\section{A ATUAÇÃO DAS AGÊNCIAS REGULADORAS DE ENERGIA PARA 0 DESENVOLVIMENTO SUSTENTÁVEL: ANÁLISE COMPARADA ENTRE BRASIL E PORTUGAL}

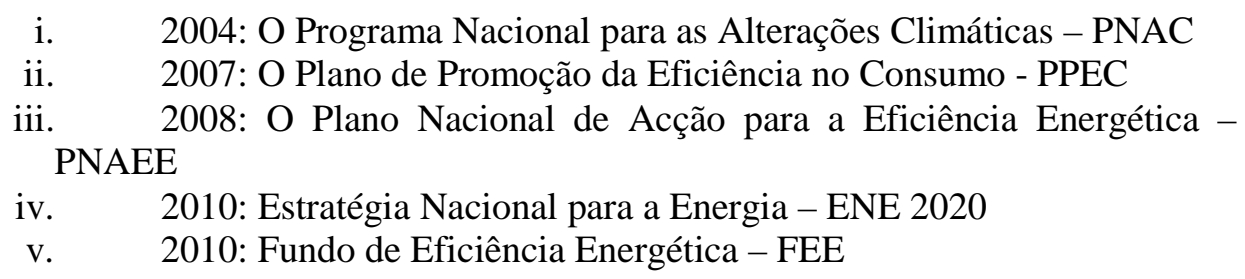

Sem sombra de dúvidas, o PNAEE é o plano que possui maior peso, devido ter surgido com base na Diretiva da União Europeia no 2006/32/CE ${ }^{6}$ (GOMES, 2016a). Inicialmente tinha como meta o ano de 2015, com a melhoria da eficiência energética equivalentes a $10 \%$ do consumo final de energia e abrangia áreas distintas, quais sejam: transporte, indústria, Estado e residencial e serviços.

Ocorre que, em 2012 a União Europeia através da Diretiva 2012/27/EU inseriu uma nova meta para eficiência energética, aumentando esta para 20\% em 2020, devido ter deparando-se com resultados nada animadores através do levantamento do PNAE 2008-20157. (GOMES, 2016a)

As novas metas para Portugal, no que diz respeito à nova diretiva da União Europeia para 2020, traduzem-se em objetivos concretos, quais sejam:

1. $20 \%$ de redução de gases de efeito de estufa;

2. $20 \%$ de incorporação de fontes de energias renováveis no consumo de energia final;

3. 20\% de redução do consumo de energia (GOMES, 2016, p. 25b).

\footnotetext{
${ }^{6}$ Como bem observou Carla Amado Gomes: "Pouco depois, na sequência da directiva 2006/32/CE, foi aprovado, pela Resolução do Conselho de Ministros n. ${ }^{\circ}$ 80/2008, de 20 de Maio, o primeiro Plano Nacional de Aç̧ão para a Eficiência Energética (PNAEE) período de 2008-2015, no qual eram contempladas quatro áreas específicas de actuação: Transportes; Residencial e Serviços; Indústria; e Estado, além de três áreas designadas 'transversais': Comportamentos; Fiscalidade e Incentivos; e Financiamentos. Nessa ocasião, foi também anunciada a criação do Fundo de Eficiência Energética, que tinha por objetivo financiar os programas e as medidas previstos no PNAEE (que veio a ser criado pelo Decreto-Lei n. ${ }^{\circ}$ 50/2010, de 20 de Maio).” In: GOMES, Carla Amado. Eficiência Energética em Portugal: uma panorâmica geral. Revista e-Pública. Volume 3, Dezembro de 2016, p. 298.

${ }^{7}$ Com efeito, e como se pode extrair dos considerandos da Resolução n. ${ }^{\circ}$ 20/2013, "O diagnóstico da execução do PNAEE 2008-2015 e do PNAER 2010 [Plano Nacional de Acção para as Energias Renováveis] permitiu concluir que, relativamente ao indicador por excelência da eficiência energética da economia, Portugal apresenta hoje uma intensidade energética da energia primária em linha com a União Europeia (UE), mas que este valor oculta um resultado menos positivo quando medida a intensidade energética da energia final. Na realidade, o elevado investimento feito por Portugal em energias renováveis e o reduzido consumo energético no setor residencial, comparativamente com o resto da Europa, encobrem uma intensidade energética da economia produtiva 27\% superior à média da União Europeia. Este resultado vem reforçar a necessidade de intensificar os esforços na atuação direta sobre a energia final, no âmbito do PNAEE, em particular da economia produtiva, por oposição a um maior nível de investimento na oferta de energia, sem pôr em causa o necessário cumprimento das metas de incorporação de energias renováveis no âmbito do PNAER”. In: GOMES, Carla Amado. Eficiência Energética em Portugal: uma panorâmica geral. Revista e-Pública. Volume 3, Dezembro de 2016, p. 299.
} 
Na intenção de superar o resultado não satisfatório anterior, o governo português comprometeu-se em uma meta ainda mais ousada do que foi proposta pela União Europeia, instituindo o Plano Nacional de Acção para as Energias Renováveis (PNAER) ${ }^{8}$ (GOMES, 2016a). Assim, declarou que aumento de:

1. $\quad 31 \%$ de FER no Consumo Final Bruto de Energia;

2. $10 \%$ de FER nos Transportes;

3. 20\% de redução do consumo de Energia Primária (GOMES, 2016, p. 300).

Assim, o PNAEE ${ }^{9}$ foi aprovado para o período de 2013-2016, através da Resolução do Conselho de Ministros n. ${ }^{\circ}$ 20/2013, de 10 de abril. (GOMES, 2016b)

Observou-se, que de fato, o governo português teve como preocupação colocar em prática os plano de eficiência energética, como demonstram os programas de transporte: Renove Carro, Mobilidade Urbana e Sistema de Eficiência Energética nos Transportes; os programas residenciais e serviços: Renove Casa \& Escritório, Sistema de Eficiência Energética nos Edifícios e Renováveis na Hora e Programa Solar; Indústria: Sistema de Eficiência Energética na Indústria; Estado: Eficiência Energética no Estado; Comportamentos: Programa Mais e Operação E.; Agricultura: (o qual ainda não teve programa por ter sido implementado por último).

\footnotetext{
${ }^{8}$ Um aspecto a realçar deste PNAEE, ainda em sede geral, é a sua associação ao Plano Nacional de Acção para as Energias Renováveis (PNAER). O Governo entendeu revê-los em simultâneo, atualizando em matéria de energias renováveis as diretrizes traçadas em 2010, uma vez que se pretende o "alinhamento dos respetivos objetivos em função do consumo de energia primária e da necessária contribuição do setor energético para a redução de emissões de gases com efeito de estufa", com vista a facilitar "os processos de decisão, nomeadamente os que envolvam opções entre investir na eficiência energética ou na promoção do uso de energias renováveis, tornando-os mais claros e racionais”. In: GOMES, Carla Amado. Eficiência Energética em Portugal: uma panorâmica geral. Revista e-Pública. Volume 3, Dezembro de 2016, p. 300.

${ }^{9}$ O PNAEE é um instrumento de planeamento energético que estabelece o modo de alcançar as metas e os compromissos internacionais assumidos por Portugal em matéria de eficiência energética que comporta as seguintes linhas orientadoras:

- Aumentar a eficiência energética da economia e em particular no sector Estado, contribuindo para a redução da despesa pública e a competitividade das empresas;

- Cumprir todos os compromissos assumidos por Portugal de forma economicamente mais racional; • Reforçar a monitorização e acompanhamento das diversas medidas;

- Reavaliar medidas com investimentos elevados e fusão de atuais medidas;

- Lançar novas medidas a partir das existentes abrangendo novos sectores de actividade (ex.: Agricultura);

- Aumento da eficiência energética no sector Estado, consubstanciado pelo programa Eco.AP, (O caderno de encargos foi aprovado pela Portaria n. ${ }^{\circ}$ 60/2013). ABREU ADVOGADOS .In: GOMES, Carla Amado (coord.). O Direito da Energia em Portugal: cinco questões sobre "o estado da arte”. Edição ICJP. Centro de Investigação de Direito Público. Faculdade de Direito da Universidade de Lisboa. Lisboa: 2016, p. 25.
} 


\section{A ATUAÇÃO DAS AGÊNCIAS REGULADORAS DE ENERGIA PARA 0 DESENVOLVIMENTO SUSTENTÁVEL: ANÁLISE COMPARADA ENTRE BRASIL E PORTUGAL}

Acredita-se que seja louvável a posição de Portugal em tentar retomar o tempo perdido no quesito da eficiência energética. O fato deste país ser parte da União Europeia talvez tenha sido fator crucial para que pudesse acompanhar os demais países europeus, que há tempos já adotam medidas para implementar a sustentabilidade em suas políticas públicas.

No mais, Luísa Schimidt (2016) aponta como tendências positivas: A redução da taxa de dependência externa do país em energia (considerada no seu todo, incluindo o grande $<<$ peso $>>$ dos transportes), atingindo em 2014 o valor mais baixo das últimas duas décadas: 71\%; e a aprovação dos Planos Nacionais de Ação para a Eficiência Energética (PNAE 2008 e 2013-2016), que originaram algumas medidas de eficiência energética, nomeadamente nos edifícios da Administração Pública.

Ressalta-se que é perceptível que a mobilidade urbana ainda consta como entrave para Portugal, contudo o programa da União Europeia Sharing Cities, co-financiado pelo Horizonte 2020 pretende colocar Lisboa na vanguarda da revolução tecnológica da gestão urbana sustentável. O programa tem como objetivo solucionar problemas das áreas de mobilidade, poluição e energia, contando com soluções de alta tecnologia para as cidades. (REVISTA SMART CITIES, 2017).

Outro entrave a Portugal, é, sem dúvidas, as tarifas empregadas pelas fontes de energias renováveis, como a eólica. De fato, trata-se de energia limpa, porém os seus custos para o oferecimento e implementação ainda são altos por se tratar de tecnologia de ponta, por isso as tarifas advindas destas energias são mais dispendiosas.

É o que relata “o despacho 7087/2017, publicado em 14 de agosto, que determina que nos procedimentos para autorização do sobreequipamento de centros electroprodutores [eólicos], isto é, para aumento de produção, a Direcção-Geral de Energia e Geologia (DGEG) tem que consultar a Entidade Reguladora dos Serviços Energéticos (ERSE) sobre os impactos para a tarifa da autorização relativa ao sobreequipamento em causa, sendo que "só deve ser autorizada desde que não tenha efeitos negativos para o Sistema Eléctrico Nacional" (JORNAL ECONÔMICO, 2017).

No Brasil, os programas de eficiência energética também são parte antes mesmo do surgimento da ANEEL (DOMINGUES, 2016). A saber:

1. O primeiro programa embrionário foi o Programa Brasileiro de Etiquetagem (PBE), em 1984; 
2. O Programa Nacional de Conservação de Energia Elétrica (PROCEL), em 1985;

3. E o Programa Nacional de Racionalização do Uso de Derivados do Petróleo e Gás Natural (CONPET), em 1991.

Após a surgimento da ANEEL em 1997, o governo brasileiro sancionou a Lei Eficiência Energética, Lei $n^{\circ}$ 10.295/2001, a qual dispõe em seu preâmbulo sobre "Política Nacional de Conservação e Uso Racional de Energia e dá outras providências”. Composta de apenas seis artigos, esta lei trata essencialmente da necessidade de mensuração do gasto energético de aparelhos consumidores de energia e um programa de metas de progressiva evolução.

É de responsabilidade da ANEEL regulamentar os investimentos em Pesquisa e Desenvolvimento (P\&D) e Eficiência Energética (EE), as duas linhas de frente deste programa são: a busca por inovações tecnológicas e o combate ao desperdício de energia.

No ano 2000 foi sancionada a Lei $n^{\circ}$. 9.991/2000 com o fulcro de disponibilizar a realização de investimentos em pesquisa, desenvolvimento e em eficiência energética por parte das empresas concessionárias, permissionárias e autorizadas do setor de energia elétrica ${ }^{10}$.

Contudo este relatório irá se ater ao Programa de Eficiência Energética (PEE) criado pela ANEEL. O início deste programa deu-se no ano de 1998 e consiste basicamente em obrigar as permissionárias e concessionárias de serviços públicos na área de energia, para aplicar em programas de eficiência energética.

Atualmente a concessionária que acumular na Conta de Eficiência Energética montante superior à obrigação legal dos últimos dois anos estará sujeita às penalidades previstas na Resolução Normativa no 063, de 12 de maio de 2004. A ANEEL também regulamentou a Resolução Normativa No 556, de 18 de junho De 2013 a qual aprova os Procedimentos do Programa de Eficiência Energética - PROPEE.

Sobre os resultados obtidos pelo programa entre 1998 a 2015, um total de Investimentos: 5,7 bilhões de reais; cerca de 4.000 projetos aprovados; uma economia de Energia Acumulada no período em torno de 46 TWh; e a retirada de Demanda na Ponta 2,3 GW. (RELATÓRIOS ANEEL, 2017).

\footnotetext{
${ }^{10}$ Em 2004, surgiram as Leis n ${ }^{\circ} 10.847$ e 10.848. A primeira autoriza a criação da Empresa de Pesquisa Energética - EPE e dá outras providências. A segunda, dispõe sobre a comercialização de energia elétrica, e dá outras providências.
} 


\section{A ATUAÇÃO DAS AGÊNCIAS REGULADORAS DE ENERGIA PARA 0 DESENVOLVIMENTO SUSTENTÁVEL: ANÁLISE COMPARADA ENTRE BRASIL E PORTUGAL}

É inquestionável que os resultados são benéficos, visto que no Brasil atualmente conseguiu aumentar a abrangência da rede elétrica, em contrapartida assegurando que o consumidor de baixa renda consiga pagar uma tarifa razoável e que possua eletrodomésticos que tenham melhor custo benefício energético.

Por outro lado, vê-se o quanto ainda é incipiente a política pública brasileira para o desenvolvimento da sustentabilidade através da eficiência energética. Os resultados ainda que positivos, devem-se muito pela abundância de recursos naturais que o país possui para a geração de energia limpa, porém não há nada ainda pensado para a mobilidade urbana, como a menor utilização de automóveis particulares em detrimento dos transportes públicos.

A Empresa de Pesquisa Energética - EPE, divulgou através do Plano Nacional de Energia 2030 que as projeções são favoráveis a conservação potencial energético do país, contudo não disponibiliza quais são as estratégicas políticas e tecnológicas para o alcance das metas.

\section{CONSIDERAÇÕES FINAIS}

Diante do que foi exposto neste trabalho, sem dúvidas, o princípio do desenvolvimento sustentável é difundido tanto no Brasil, quanto em Portugal. Percebe-se que, de fato, não há mais espaço para teorias especulativas que questionam a real necessidade de preservar o meio ambiente para as futuras gerações.

Deve-se muito ao papel desempenhado pelo Direito e seus operadores, que vem divulgando esta realidade para além das cortes e das salas de aula. Hoje, há uma percepção que a temática ambiental necessita do engajamento social para que resulte na transformação que se espera para o mundo. Acredita-se que uma das formas mais eficazes para que haja essa mudança de paradigma é a conscientização social aliada a uma hard law que puna com rigor pessoas físicas e jurídicas que ponham seus interesses à frente da proteção ambiental.

Quando fora exposto o problema sustentabilidade frente ao setor elétrico, ficou translúcido que tanto no Brasil, quanto em Portugal, existem leis completamente alinhadas com o princípio do desenvolvimento sustentável. Sendo que estes são defendidos de modo expresso em suas Cartas Magnas.

Porém, quando se adentra na questão específica da regulação para o setor elétrico, vê-se que Portugal tem um olhar mais cuidadoso com as causas ambientais, que o Brasil. As 
leis portuguesas, para além de estarem mais bem redigidas no que tange ao novo paradigma da sustentabilidade, também estão mais alinhadas com o que se espera sobre a eficiência energética no âmbito das agências reguladoras.

O Brasil, um gigante pela própria natureza, como bem afirma o hino pátrio, não possui legisladores à altura do seu potencial. Embora, tenha leis suficientes que tratem do problema da regulação para uma melhoria dos recursos energéticos em questão. Neste caso, compara-se bem que em Portugal no Conselho da ERSE há representantes especialistas em meio ambiente, para alinhar os interesses da entidade ao que prega os novos interesses ambientais para área da energia, notadamente, o fomento de uma política pública que assegure a eficiência energética.

Como mencionou Rui Pena, Portugal “acordou tarde para a eficiência energética”, tal frase tem encaixe perfeito quando utilizada a sua ex-colônia, o Brasil. Ambas as nações se encontram no início de uma jornada longa quando se objetiva a adequação dos parâmetros da sustentabilidade com relação ao setor elétrico. (GOMES, 2016a)

Portugal apresenta resultados tímidos perto das demais maiores nações da União Europeia, contudo os esforços das últimas décadas precisam ser reconhecidos. Com políticas públicas de incentivo à variação da matriz energética em energias renováveis, Portugal superou as expectativas no investimento de parques eólicos. Contudo, o potencial para energia solar ainda não é bem aproveitado.

O Brasil, em índices de energia limpa continua com saldo positivo, mas esconde que é praticamente dependente das hidrelétricas, mesmo tendo potencial para a melhor exploração de outros tipos de energias renováveis como a eólica e a solar. O país continua preso a políticas de expansão de malha elétrica e incentivo do uso da certificação de eficiência energética, o que se julga muito incipiente perante os novos desafios do setor elétrico.

Notadamente o PNAEE e PEE são os dois programas criados para a implementação da eficiência energética em Portugal e no Brasil, com grande alcance. Contudo, em linhas comparativas Portugal tem larga vantagem sobre o Brasil, pois percebe-se que as áreas de atuação do PNAEE e os programas derivados deste, são inigualavelmente mais abrangentes que o brasileiro.

Por fim, compreende-se que o caminho para a sustentabilidade no quesito eficiência energética, é longo para ambos os países, mas há um otimismo maior no caso português.

\section{REFERÊNCIAS}




\section{A ATUAÇÃo DAS AGÊNCIAS REGULADORAS DE ENERGIA PARA 0 DESENVOLVIMENTO SUSTENTÁVEL: ANÁLISE COMPARADA ENTRE BRASIL E PORTUGAL}

BRASIL. Agência Nacional de Energia Elétrica. Ministério de Minas e Energia. Disponível em: http://www.aneel.gov.br/a-aneel acesso em 01/09/2017

CONFRARIA, João. Regulação e Concorrência, Desafios do século XXI. $2^{\text {a }}$ Edição Revista e Actualizada. Universidade Católica Editora. Lisboa: 2011.

CORREIA, Mariana. Sustentabilidade: Conceito e Desenvolvimento. In: Energias Renováveis.

GONÇALVES, António Lobo (org.). Energias Renováveis. Edição Atelier Nunes e Pã. Porto, 2009, p. 71.

DIRECÇÃO-GERAL DA ENERGIA. Gás Natural: Perspectivas. Energia, nº 0. Lisboa: 1997.

DOMINGUES, Edson Paulo e outro. Aumento da Eficiência Energética no Brasil: uma opção para a economia de baixo carbono. Revista de Economia Aplicada, v. 20, n. 3, 2016, p. 279.

FERNANDES, Eduardo de Oliveira. A Energia do Nosso Dia-a-Dia. In: Partilhar o Futuro. Esfera do Caos Editores e Fundação Calouste Gulbenkian. Lisboa: 2011, p. 11-12.

GNESOTTO, Nicole; GREVI, Giovanni. O mundo em 2025 Segundo os Especialistas da União Européia. Editora Bizâncio. Lisboa: 2008.

GOMES, Carla Amado. Eficiência Energética em Portugal: uma panorâmica geral. Revista e-Pública. Volume 3, Dezembro de 2016.

GOMES, Carla Amado (coord.). O Direito da Energia em Portugal: cinco questões sobre “o estado da arte”. Edição ICJP. Centro de Investigação de Direito Público. Faculdade de Direito da Universidade de Lisboa. Lisboa: 2016.

IPCC, 2007, Intergovernmental Panel on Climate Change. Constributions of Working Group I, II and III to the IPCC Fourth Assessment Report, Cambridge University Press.

JORNAL ECONÓMICO. EDP contesta intenção do Governo de travar produção eólica adicional a preço garantido. 13 de setembro de 2017 às 07:26. http://www.jornaldenegocios.pt/empresas/energia/detalhe/edp-contesta-intencao-do-governode-travar-producao-eolica-adicional-a-preco-garantido Acesso em 29/09/2017.

JUSTEN FILHO, Marçal. Curso de Direito Administrativo. 4. ed. rev. atual., São Paulo: Saraiva, 2009.

KISS, Alexandre. Direito Internacional do Ambiente. In: Direito do Ambiente. Diogo Freitas do Amaral/Marta Tavares de Almeida (org.), Instituto Nacional de Administração. Oeiras: 1994. 
MILARÉ, Édis. “Amplitude, Limites e Prospectivas do Direito do Ambiente”. In: MARQUES, José Roberto (org.) Sustentabilidade e Temas Fundamentais de Direito Ambiental. Campinas: Millennium, 2009.

PECES-BARBA MARTÍNEZ, Gregorio. Derecho y derechos fundamentales, Madrid, 1993.

PORTUGAL. Entidade Reguladora de Serviços Energéticos. Ministério da Economia. Disponível em: http://www.erse.pt/pt/aerse/Paginas/default.aspx Acesso em 01/09/2017.

RAHMSTORF, D. A Semi-empirical approach to projecting future sea-level rise. Science, 368370.

RELATÓRIOS ANEEL. Calculadora 2050 e Eficiência Energética Programa de Eficiência Energética Regulado pela ANEEL - PEE. Rio de Janeiro - RJ, 28/03/2017. Disponível em: http://www.aneel.gov.br/documents/656831/14930475/Calculadora/57448ec1-7347-1207a0d7-7be72e5d894b. Acesso em 29/09/2017.

REVISTA SMART CITIES. Cidades Sustentáveis. Nº 14. Jan/Fev/Mar 2017. p, 43-45.

ROQUE, Ana. Regulação do Mercado — novas tendências. Quid Juris, Lisboa: 2004.

SANDS, Phillipe. Principles of Internacional Law. 2nd ed. Cambridge University Press. Disponível em: www.cambridge.org/9780521817943 Acesso em 15/07/2017. Acesso em: 12/09/2017.

SANTOS, Filipe Duarte. Os desafios do desenvolvimento sustentável. In: Partilhar o Futuro. Esfera do Caos Editores e Fundação Calouste Gulbenkian. Lisboa: 2011.

SARAIVA, Rute Neto Cabrita. A Herança de Quioto em Clima de Incerteza: análise jurídico-económica do mercado de emissões num quadro de desenvolvimento sustentado. Tese de doutoramento, Ciências Jurídico-Económicas (Economia Política), Universidade de Lisboa, Faculdade de Direito, 2010, p. 269. Disponível em: http://repositorio.ul.pt/handle/10451/2237. Acesso em: 20/08/2017

SCHMIDT, Luísa. Portugal: Ambientes de Mudanças - Erros, Mentiras e Conquistas. Temas e Debates. Círculo de Leitores. Lisboa: 2016.

SILVA, Vasco Pereira da. Verde Cor de Direito. $2^{\text {a }}$ ed. Ed: Almedina. Coimbra: 2005 SOARES, Cláudia Dias; e outro. Direito das Energias Renováveis. Editora Almeida. Coimbra: 2014. 